\title{
Diabetes Mellitus is a Predictor for Poor Outcome After Total Knee Replacement: A Matched Cohort Study
}

\author{
Nouman memon ${ }^{1 *}$, Sajid Younus ${ }^{2}$, Shahid Noor ${ }^{3}$, Faizan Iqbal ${ }^{4}$ and Farhan Haroon ${ }^{5}$ \\ Department of orthopedic surgery, Liaquat national hospital, Pakistan
}

Submission: July 24, 2019; Published: August 26, 2019

*Corresponding author: Noumanmemon, Department of orthopedic surgery, Liaquat national hospital, Pakistan

\begin{abstract}
Objective: The aim of this study was to compare the clinical outcome between diabetic and non-diabetic patients after total knee replacement

Material and methods: 351 patients were diagnosed as type 2 diabetes mellitus (T2DM) preoperatively. These patients were matched case to case with 351 nondiabetic patients who underwent bilateral TKR in the same duration with respect to age, gender, BMI and functional status (determined by Range of motion and knee society score) at baseline.
\end{abstract}

Results: At 1 year follow up, there was insignificant difference in Range of motion and knee score component of knee society score (KSS). The functional score component of KSS was better in non-diabetic group $(\mathrm{p}=0.04)$.

Conclusion: The functional outcome of TKR is not determined by Diabetes because there is no statistical difference in Range of motion and knee score when compared between diabetic and non-diabetic patients and there is a valid difference in function score which could be related with other co-morbidities in diabetic patients.

Keywords: Diabetes, arthroplasty, total knee, outcome

\section{Introduction}

Total Knee Arthroplasty (TKA) is now a day a common procedure done to improve quality of life in deformed or unstable and moderate to severe painful knee joints. The most important factor which determines the success of knee arthroplasty is range of motion. For knee to function normally between 83 and $105^{\circ}$ of flexion is required [1]. A reduction in Range of motion (ROM) at the knee joint is associated with decreased mobility, compromise independence and pain [2]. Diabetes mellitus, is one of the common diseases worldwide, reported prevalence of over 180 million [3] people. Few studies showed unfavorable functional outcome in patients with diabetes than non-diabetics [4-6]. Meding et al. [4] and Robertson et al. [5] assessed the functional outcome after total knee replacement and they used the Knee Society Score (KSS) [7], the diabetic patients had worse outcome compared non-diabetic patients. Moon et al. [6] on the other hand, using the similar functional outcome tool, reported no significant difference in the outcome in diabetic as well as non-diabetic patients. However, all the above-mentioned studies are retrospective case control studies.
The durability of implants for total knee arthroplasty (TKA) has promising results in the recent decades with less failure rates [8], the main aim of arthroplasty outcomes is patientreported outcomes (PROs), including pain score, functional improvement, quality of life and satisfaction after surgery [9]. Our hypothesis is that diabetes is independently related with poorer functional outcomes after primary TKA, diabetic patients with complications would have even poor functional outcomes and that this relation is also associated multiple co morbidities and multiple joints involvement in diabetic patients.

\section{Material and Method}

We evaluated the data of the patients undergoing simultaneous bilateral TKR for primary Osteoarthritis from April 2014 to May 2016 by a single surgeon from Pakistan national joint registry (PNJR). Of this, 351 patients were diagnosed as type 2 diabetes mellitus (T2DM) preoperatively. These patients were matched case to case with 351 non diabetic patients who underwent bilateral TKR in the same duration with respect to age, gender, BMI and functional status (determined by ROM and knee society score) .The demographic details and baseline 


\section{Orthopedics and Rheumatology Open Access Journal (OROAJ)}

functional status of all the patients were recorded at the preoperative assessment clinic and documented in PNJR. Other comorbidities of the patients were also recorded. The study was approved by the ethics review committee of hospital

Knee society score (KSS) has two divisions, knee score and function score. Both scores are given 100 numbers each. Knee score determine the condition of the joint including parameters are pain ( 50 points), range of movement (25 points) and stability (25 points) and deductions is for flexion contracture, extensor lag and malalignment. Function score addressed the mobilization status of the patient and included the walking distance (50 points) and the ability to climb stairs (50 points) and deductions is for using any walking aids.

All the patients underwent simultaneous bilateral TKR by a single surgeon with same surgical technique. Posterior stabilizing implant was used in all patients. All patients received similar postoperative rehabilitation. Patients with secondary OA and other causes of arthritis of knee were excluded. The diabetic patients with other systemic complications were excluded. The patients were followed up in OPD at 2 weeks, 6 weeks, 3 months, 6 months, 1 year and 2 year post-operatively. The functional outcome tools i.e. ROM, knee score and functional score was determined by the surgeon using goniometer and documented in PNJR. We took the outcome measures of 2 year follow up for our study. Patient's demographic details and all preoperative and postoperative data were recorded in a questionnaire. Statistical analysis was done using SPSS version 20.

\section{Results}

Out of 351 patients of both groups, $62 \%$ of patients were females. The difference in mean BMI $(p=0.08)$ and mean age of patients of both groups $(\mathrm{p}=0.06)$ were statistically insignificant. (Table 1) Diabetic patients had high incidence of other comorbidities ( $p=0.02,0.06)$. The ROM and functional status of the patients of both groups were similar (Table 2). At 2 year follow up, there was insignificant difference in ROM and knee score component of knee society score (Table 3 ). The function score component of KSS was better in non-diabetic group $(p=0.04)$.

Table 1: Demographic Data.

\begin{tabular}{|c|c|c|c|}
\hline Characteristic & Diabetic (n=350) & Non-diabetic(n=350) & p-value \\
\hline Mean age in years & 65 & 69 & 0.06 \\
\hline Gender: Female (\%) & $217(62)$ & $217(62)$ & 0.08 \\
\hline Mean BMI in kg/m2 & 33.56 & 31.27 & \\
\hline Other co-morbidities & & & 0.02 \\
\hline 1) HTN (\%) & $134(34)$ & $92(26)$ & 0.06 \\
\hline 2) IHD (\%) & $62(17)$ & $48(14)$ & \\
\hline
\end{tabular}

Table 2: Baseline Data.

\begin{tabular}{|c|c|c|c|}
\hline Characteristic & Diabetic & Nondiabetic & p-value \\
\hline Mean ROM Rt knee & 92.22 & 93.54 & 0.12 \\
\hline Mean ROM Lt knee & 94.17 & 95.13 & 0.1 \\
\hline Mean Knee score Rt knee & 27 & 29 & 0.09 \\
\hline Mean knee score Lt Knee & 31 & 29 & 0.08 \\
\hline Function score & 37 & 36 & 0.18 \\
\hline
\end{tabular}

Table 3: At Two Year Follow-Up.

\begin{tabular}{|c|c|c|c|}
\hline Characteristic & Diabetic & Nondiabetic & p-value \\
\hline Mean ROM Rt knee & 103.21 & 105.11 & 0.11 \\
\hline Mean ROM Lt knee & 106.97 & 104.85 & 0.09 \\
\hline Mean Knee score Rt knee & 75 & 77 & 0.06 \\
\hline Mean knee score Lt Knee & 79 & 80 & 0.12 \\
\hline Function score & 85 & 89 & 0.04 \\
\hline
\end{tabular}

\section{Discussion}

There is unfavorable evidence as to whether diabetes mellitus alters the functional outcome and patient satisfaction after a total knee replacement (TKR). The main objective of our study was to assess that a diagnosis of diabetes mellitus preoperatively is significant independent predictors of functional outcomes at minimum two year of follow-up after TKA. Previous literature has demonstrated that the presence of diabetes mellitus has a firm association with an increased risk of morbidity and mortality [10]. In addition to this, diabetic patients have higher 
rate of post-operative complications which includes superficial and deep wound infections (1.2 to $12 \%$ ) [11-15], and aseptic loosening. Meding et al. and Robertson et al. reported that functional outcome after TKA in diabetic patients assessed with Knee Society Score (KSS) were significantly worse compared to non-diabetics. The results of present study are however conflicting. Those with diabetes have a inferior functional Knee Society Score at the post-operative period as compared to nondiabetes, as maybe expected. To establish a firm association whether or not a diagnosis of diabetes affects the post-operative outcome the results should have been matched for baseline values or taken on a case by case basis as was performed in our study.

There was no difference in clinical outcome between diabetic and non-diabetic patients as reported by Moon et al. The present study has comparable results as there is no statistical difference in knee score and ROM but major difference in function score is probably related to co-morbidities present in diabetic patients. Both groups which were chosen in this cohort are homogenous in that the patients consisted of those with a diagnosis of osteoarthritis attending the OPD for TKR and it is one of the strengths of our study. Only patients with Type 2 diabetes mellitus were included. All patients underwent the same surgical procedure and were followed-up for a minimum period of 2 year by the same surgeon. Previous literature has demonstrated that pre-operative range of motion (ROM) is the strongest predictor of post-operative ROM [16] Thus we matched the patients on a case by case basis for ROM we can precisely demonstrate that diabetes affects the outcome after TKA.

Our study also has few limitations which need to be mentioned. We assessed the ROM using simple goniometer which has a high rate of operator depended errors in assessing range of motion, flexion contracture, and extension lag in knee examinations [17-19]. The standard other methods including electro goniometry, gait analysis and radiographic examination could not be used because of large numbers of patients involved and the ethical issues regarding radiation exposure for research works. We were unable to collect the data regarding duration of diabetes because previous literature have established a strong relation between restricted joint movements and duration of diabetes, thus the question as to whether the cutoff duration of diabetes after which we might assume a poor functional outcome after total knee arthroplasty, could not be determined in our study [20-22]. Also, the diabetic control (HbA1c concentration) information was not recorded.

It is concluded that diabetic patients probably have a less function score after TKA as compared to non-diabetic patients, but knee score and ROM have no association with diabetes at 2-year follow-up after TKR. We feel that it is the utmost duty of a surgeon to counsel the patient before procedure that because of the underlying co-morbidities, their functional outcome postoperatively is expected to be less than the non-diabetic patients.

\section{Conflict of Interest}

The Authors declare no conflict of Interest.

\section{References}

1. Laubenthal KN, Smidt GL, Kettelkamp DB (1972) A quantitative analysis of knee motion during activities of daily living. Phys Ther 52(1): 34-43.

2. Ritter MA, Campbell ED (1987) Effect of range motion on the success of a total knee arthroplasty. J Arthroplasty 2(2): 95-97.

3. WHO Fact sheet on diabetes (2010).

4. Meding JB, Reddleman K, Keating ME, Klay A, Ritter MA, et al. (2003) Total knee replacement in patients with diabetes mellitus. Clin Orthro Relat Res 416: 208-216.

5. Robertson F, Geddes J, Ridley D, McLeod G, Cheng K (2012) Patients with Type 2 diabetes mellitus have a worse functional outcome post knee arthroplasty: a matched cohort study. Knee 19(4): 286-289.

6. Moon HK, Han CD, Yang IH, Cha BS (2008) Factors affecting outcome after total knee arthroplasty in patients with diabetes mellitus. Yonsei Med J 49(1): 129-137.

7. Insall JN, Dorr LD, Scott RD, Scott WN (1989) Rationale of the knee society clinical rating system. Clin Orthop Relat Res 248: 13-4.

8. Rand JA, Trousdale RT, Ilstrup DM, Harmsen WS (2003) Factors affecting the durability of primary total knee prostheses. J Bone Joint Surg Am 85(2): 259-265.

9. OrthoInfo (2011) Total Knee Replacement. American Academy of Orthopaedic Surgeons, USA.

10. Dhungel B, Diggs BS, Hunter JG, Sheppard BC, Vetto JT, Dolan JP (2010) Patient and perioperative predictors of morbidity and mortality after oesophagectomy: American College of Surgeons National Surgical Quality Improvement Program (ACSNSQIP), 2005-2008. J Gastrointest Surg 14(10): 1492-1501.

11. England SP, Stern SH, Insall JN, Windsor RE (1990) Total knee arthroplasty in diabetes mellitus. Clin Orthop Relat Res 260: 130-134.

12. Serna F, Mont MA, Krackow KA, Hungerford DS (1994) Total knee arthroplasty in diabetic patients. Comparison to a matched control group. J Arthroplasty 9(4): 375-379.

13. Yang K, Yeo SJ, Lee BP, Lo NN 2001 Total knee arthroplasty in diabetic patients: a study of 109 consecutive cases. J Arthroplasty16(1): 102106.

14. Papagelopoulos PJ, Idusuyi OB, Wallrichs SL, Morrey BF (1996) Long term outcome and survivorship analysis of primary total knee arthroplasty in patients with diabetes mellitus. Clin Orthop Relat Res 330: 124-132.

15. Meding JB, Reddleman K, Keating ME, Klay A, Ritter MA, Faris PM, et al. (2003) Total knee replacement in patients with diabetes mellitus. Clin Orthop Relat Res 416: 208-216.

16. Ritter MA, Harty LD, Davis KA, Meding JB, Berand MA (2003) Predicting range of movement after total knee arthroplasty. J Bone Joint Surg Am 85:1278-1285.

17. Brosseau L, Tousignant M, Budd J, Chartier N, Duciaume L et al. (1997) Intratester and intertester reliability and criterion validity of the parallelogram and universal goniometers for active knee flexion in healthy subjects. Physio Res Intl 2(3): 150-166. 
18. Mayerson NH, Milano RN (1984) Goiniometric measurement reliability in physical medicine. Arch Phys Med Rehabil 65(2): 92-94.

19. Rothstein JM, Miller PJ, Roettger RF (1983) Goniometric reliability in a clinical setting; elbow and knee measurements. Phys Ther 63(10): 1611-1615.

20. Brik R, Berant M, Vardi P (1991) The scleroderma-like syndrome of insulin-dependent diabetes mellitus. Diabetes Metab Rev 7(2): 121128
21. Arkkila PET, Kantola IM, Viikari JSA, Ronnemaa T, Vahatalo MA (1996) Limited joint mobility is associated with the presence but does not predict the development of microvascular complications in type 1 diabetes. Diabet Med13(9): 828-833.

22. Schulte L, Roberts MS, Zimmerman C, Ketler J, Simon S (1993) A quantitative assessment of limited joint mobility in patients with diabetes. Arthritis Rheum 36(10): 1429-1443.

\section{Your next submission with Juniper Publishers will reach you the below assets}

- Quality Editorial service

- Swift Peer Review

- Reprints availability

- E-prints Service

- Manuscript Podcast for convenient understanding

- Global attainment for your research

- Manuscript accessibility in different formats ( Pdf, E-pub, Full Text, Audio)

- Unceasing customer service

Track the below URL for one-step submission https://juniperpublishers.com/online-submission.php 